Research Institute for Quantitative Studies in Economics and Population Faculty of Social Sciences, McMaster University

Hamilton, Ontario, Canada

L8S 4M4

\title{
POPULATION CHANGE AND THE REQUIREMENTS FOR PHYSICIANS: THE CASE OF ONTARIO
}

\author{
Frank T. Denton \\ Amiram Gafni \\ Byron G. Spencer
}

QSEP Research Report No. 355

September 2000

The authors are QSEP Research Associates. Frank Denton and Byron Spencer are members of the McMaster Department of Economics. Amiram Gafni is a member of the McMaster Department of Clinical Epidemiology and Biostatistics.

This report is cross-listed as No. 29 in the McMaster University SEDAP Research Paper Series.

The Research Institute for Quantitative Studies in Economics and Population (QSEP) is an interdisciplinary institute established at McMaster University to encourage and facilitate theoretical and empirical studies in economics, population, and related fields. For further information about QSEP and other reports in this series, see our web site http://socserv2.mcmaster.ca/qsep. The Research Report series provides a vehicle for distributing the results of studies undertaken by QSEP associates. Authors take full responsibility for all expressions of opinion. 


\begin{abstract}
$\underline{\text { ABSTRACT }}$
POPULATION CHANGE AND THE REQUIREMENTS FOR PHYSICIANS:

THE CASE OF ONTARIO

Frank T. Denton, Amiram Gafni, and Byron G. Spencer

McMaster University
\end{abstract}

The effects of population change on requirements for physicians in Ontario are studied. Principal findings are the following: (a) contrary to popular belief, the overall increase in requirements will be significantly lower in 2000-2020 than in the preceding two decades; (b) population aging alone will raise the overall rate of growth of requirements but that will be more than offset by slower population growth; (c) the main effect of aging will be on the distribution of requirements among categories of physicians. These findings suggest that the emphasis on population aging in policy discussions of future overall physician requirements is unwarranted. 
September 2000

\title{
POPULATION CHANGE AND THE REQUIREMENTS FOR PHYSICIANS:
}

\section{THE CASE OF ONTARIO*}

\author{
Frank T. Denton, Amiram Gafni, and Byron G. Spencer \\ McMaster University
}

\section{INTRODUCTION}

The population of Canada is aging. The "baby boom" lasted roughly from the late 1940s to the mid 1960s, and the children of that period are now in or near middle age (depending on one's definition). Some will turn 65 in little more than a decade and all will attain that milestone within three. Fertility rates have been low -- below the natural replacement level -- for more than a quarter of a century, and with no offset at the young end of the scale the aging of the baby boom generation is thus raising the median age of the population steadily, year by year. That that trend will continue for many decades is as certain a prediction as one can ever make about the longer-term future.

\footnotetext{
* We acknowledge with appreciation the help of Christine Feaver, who carried out the calculations reported in this paper, and the Canadian Institute for Health Information, which provided us with unpublished tabulations of the age-sex distributions of expenditures on physician services. The work underlying the paper was carried out as part of the SEDAP (Social and Economic Dimensions of an Aging Population) Research Program supported by the Social Sciences and Humanities Research Council of Canada, Statistics Canada, and the Canadian Institute for Health Information.
} 
The aging of the population has important implications. It has implications for pension plans, public and private, for the age composition of the labour force, for patterns of investment and consumer expenditure, and of course for health care. Virtually all aspects of the health care system will be affected in one way or another: the requirements for physicians, nurses, and other skilled personnel, the demand for hospital beds and equipment, nursing home beds, other long-term institutional facilities, home care services for the elderly. Physicians are of course at the core of the system -- the chief decision makers at the clinical level.

How population change will affect the health care system, and in particular the demand for physicians, is a hot topic in policy debate. What is largely lacking, though, is careful discussion of "how much" and "when": How much should we expect the demand for physicians services to increase as a result of population growth and aging, and when will the effects be felt? Our aim is to provide approximate answers to those questions.

We explore the issues of "how much" and "when" with data for Ontario. Population aging, with its implications for health care, is a phenomenon common to all regions of Canada, to the United States, and to many other countries. (On population aging and the U.S. health care system, see for example Wolfe, 1993; see also the review of Wolfe's book by Sloan, 1994.) However, the Ontario data base is particularly useful for our purposes; it provides detailed age distributions of fee payments for male and female patients, by category of physician, for those physicians paid on a fee-for-service basis under the Ontario Health Insurance Plan (OHIP). Physicians paid in other ways are excluded but overall the fee-for-service data provide very high coverage ratios for the profession as a whole, and 
they are well suited to the type of analysis presented in this paper. (In the 1995-96 fiscal year, OHIP fee-for-service payments to physicians were about 98 percent of the total payments to physicians in Ontario reported in Canadian Institute for Health Information, 1998.)

The paper proceeds as follows. Section 2 presents "utilization profiles" for each of nineteen physician categories (General Practice, plus eighteen categories of specialists) -profiles that show the utilization of physician services by different age groups of the population. Section 3 provides a summary review of changes in the Ontario population over the period 1980-2000, and projections to the year 2020. Sections 4 and 5 describe the analytical framework that we use for assessing the effects of population change on the demand for physician services. Sections 6, 7, and 8 then make use of that framework to analyse and project the effects of population change on physician demand. Section 9 provides a brief statement of conclusions.

\section{THE UTILIZATION OF PHYSICIAN SERVICES: AGE PROFILES}

We begin by establishing the relationships between the utilization of physician services and age. To do that we make use of OHIP data on fee payments (unpublished) provided to us by the Canadian Institute for Health Information (CIHI). They are for the fiscal year 1995-96, which hereafter we shall refer to simply as 1995. Using those data we have constructed what we term "utilization rates" -- ratios of fee payments to population -separately for males and females, in each of nineteen age groups: five-year groups from 0-4 to 85-89, plus the group 90 and over. (The population figures used in the calculations are 
Statistics Canada estimates for July 1, 1995.) The utilization rates, represented by payments per capita in the different age groups, are plotted in Figure 1 for each of nineteen physician categories in the classification system used by CIHI (an exhaustive set) and for all categories combined.

Several features stand out in the figure. The first (not surprising) is the general tendency for utilization rates to rise with age. There are exceptions, of course: Pediatrics is an obvious one, Obstetrics/Gynecology another. The rates for Psychiatry rise until middle age, but then decline sharply. Other categories have their own distinctive features, including significant differences between male and female patterns. Most, though, reflect the more frequent use and increasing costs of physician services at older ages, implying immediately the importance of population aging for the demand for such services. But again there is an exception: while utilization rates generally rise with age, in the very oldest age groups they typically turn down. That is not true for General Practice but it is for most of the other categories, and for all categories combined. Roughly speaking, the "old old" make somewhat less use per capita of physician services -- of specialized services, in particular -- than do people in the "younger old" ages.

\section{POPULATION CHANGE, PAST AND FUTURE}

Having documented the relationships between utilization of physician services and the population we turn now to the latter. Table 1 shows the population of Ontario at five-year intervals from 1980 to 2000 and projections of it to 2020 , under seven alternative assumptions about future mortality, fertility, and the level of immigration to Canada. 
(Details of the projections are provided in the Appendix.) The 1980-2000 figures are Statistics Canada estimates (subject to a small amount of our own estimation to obtain the figure for 2000); the 2005-2020 figures were calculated using the MEDS projection software. (For a general description of MEDS, see Denton, Feaver, and Spencer, 1994; the version of MEDS that provides provincial demographic projections is known as PMEDS-D, and is described in Denton, Feaver, and Spencer, 1997.) Also shown in Table 1 are the population figures converted to index form (with base 100.0 in 2000), 5-year growth rates, median ages, and the percentages of the population in three selected age groups: under 15, 55-74, and 75 and older.

The population of Ontario has been increasing steadily since 1980 (and of course, for far longer than that) and it is projected to continue increasing during the next two decades. But the rate of growth seems almost certain to decline. The extent of the decline depends mainly on what happens to fertility and immigration, but even "high" fertility or "high" immigration (see the Appendix) is unlikely to arrest it completely. Our "standard" projection has the 5-year rate of increase falling from 6.2 percent in 1995-2000 to 4.2 percent by 2015-2020. Over the whole of the 20-year projection period the "standard" projection calls for an increase of some 2.4 million people, or about 21 percent; under the "low" immigration assumption, which produces the smallest rates of increase, the population gain is about 1.9 million, or 16 percent. Further growth in the total size of the Ontario population is virtually certain, but at slower rates.

What of the age distribution? The median age provides a simple summary measure: in 1980 it was 30.0 years; by 2000 it had risen to 36.6 , and by 2020 it is projected to be in the 
range 40.5 to 42.0, depending on which of the seven alternatives one chooses. (Our "standard" projection puts it at 41.4.) The proportion of the population under 15 has been falling steadily, and is projected to fall further $(19.5$ percent in $2000,15.7$ percent in 2020 , according to the "standard" projection). Concomitantly, the proportions in the older age groups are projected to increase -- from 16.2 to 24.3 percent for the 55-74 group, over the two decades; from 5.6 to 7.2 percent for the 75 and older group, based on the "standard" projection. Population growth will thus be accompanied by a major shift in composition as the baby boom generation moves up the age ladder. Both dimensions of population change have obvious implications for the demand for physician services.

\section{CALCULATING THE EFFECTS OF POPULATION CHANGE ON PHYSICIAN}

\section{REQUIREMENTS}

The core idea is simple. Given the age-utilization profiles for males and females in the base year, 1995, we ask, "What would be the requirements for physician services in future years, assuming the profiles to remain the same and only the population to change?" The calculation can be done for each physician category, for combinations of categories, or for all categories together. Utilization "profiles" (as we call them) have been used in earlier studies to project the impact of population change on the requirements for physicians in Ontario (Denton, Gafni, and Spencer, 1992, 1993, 1994, 1995a, 1995b) and in the U.S. (Greenberg and Cultice, 1997).

The formal framework is as follows. Let $s_{i}$ denote the $i^{\text {th }}$ clinical physician service and let $I_{p}$ be the set of all such services provided by physicians paid on a fee-for-service basis 
in physician category p. (The sets are exhaustive over all categories, but need not be mutually exclusive; some services may be provided by physicians in more than one category.) Let $f_{i}$ be the fee-for-service charge for the $i^{\text {th }}$ service, according to the OHIP fee schedule. Assuming the schedule to represent (at least approximately) the time required, complexity, and other characteristics of the different types of service, the $f_{i}$ values can be interpreted as a convenient set of relative weights for calculating an aggregate measure of the total "quantity" of services provided by each category of physician. (The actual dollar values do not matter, only the relative sizes; the $f_{i}$ values could be expressed as ratios to their average value, for example, without affecting the results in what follows.)

Let $\mathrm{Q}_{\mathrm{pjx}}=\sum_{\mathrm{i} \varepsilon \mathrm{I}_{\mathrm{p}}} \mathrm{f}_{\mathrm{i}} \mathrm{s}_{\mathrm{ijx}}$ be the total cost of all services provided by fee-for-service physicians in category $p$ to the population of sex $j$ and age $x$, or alternatively as the aggregate "quantity" of services provided to that population, calculated as the fee-weighted sum of the individual services. Defining $N_{j x}$ as the sex $j$, age $x$ population, let $\mathrm{q}_{\mathrm{pjx}}=\mathrm{Q}_{\mathrm{pjx}} / \mathrm{N}_{\mathrm{jx}}$ be the corresponding quantity of services per capita. The per capita quantities of services can thus be computed from physician billing data by age and sex of patient and corresponding population data. The differences across age-sex groups can then be interpreted as differences in per capita requirements by the different groups. The utilization profiles shown in Figure 1 can be interpreted in that way.

An index of the "pure" effects of population change can now be defined. Let the subscript $t$ denote year and set $t=0$ in a chosen base year (1995, in our case). Holding the $q$ values constant at their base year levels and letting only the population vary, the index for physician category $p$ is then 
(1) $\mathrm{R}_{\mathrm{pt}}=\left(\sum_{\mathrm{j}} \sum_{\mathrm{x}} \mathrm{q}_{\mathrm{pjxo}} \mathrm{N}_{\mathrm{j} x \mathrm{t}}\right) /\left(\sum_{\mathrm{j}} \sum_{\mathrm{x}} \mathrm{q}_{\mathrm{pjxo}} \mathrm{N}_{\mathrm{jxo}}\right)$

$\mathrm{R}_{\mathrm{pt}}$ is in the first instance an index of the quantity of services provided by clinical fee-forservice physicians. If the ratio of such physicians to the quantity of services they provide is held constant, and if the ratio of fee-for-service physicians to all physicians in category $p$ is similarly held constant (though the proportion may differ among categories), then $\mathrm{R}_{\mathrm{pt}}$ may be regarded also as an index of the total requirements for physicians in the category, allowing only for population change. The formula in equation (1) will be recognized as a version of the Laspeyres quantity index formula found in economic index theory and practice (Banerjee, 1975, for example): the $q$ variables play the role of prices, the $N$ variables the role of quantities, and the $j$ and $x$ subscripts the role of identifiers of different "commodities".

As a further step, an index for the number of physicians in all categories combined can be calculated as a weighted average of the category-specific indexes:

(2) $\mathrm{R}_{\mathrm{t}}=\sum_{\mathrm{p}} \mathrm{w}_{\mathrm{po}} \mathrm{R}_{\mathrm{pt}}$ where $\mathrm{w}_{\mathrm{po}}=\mathrm{M}_{\mathrm{po}} / \mathrm{M}_{\mathrm{o}}, \mathrm{M}_{\mathrm{po}}$ is the number of physicians in category $\mathrm{p}$ in year 0 , and $\mathrm{M}_{\mathrm{o}}=\sum \mathrm{M}_{\mathrm{po}}$ is the total number of physicians in all categories in that year. Similar indexes can be defined for groups of categories by redefining the weights in equation (2) as proportions of the group totals.

There are many factors that affect the delivery of physician services, and those factors vary over time. Population change is obviously important but (equally obviously) so too are changes in medical knowledge, technology, and delivery practices. Calculations based on equations (1) and (2) allow us simply to isolate the effects of population change from all 
other effects. Holding the $q$ values constant and interpreting the indexes as representing "pure" population-induced effects on the total number of physicians required implies freezing all other influences at their base year levels. Projections based on the equations should not be interpreted as predictions of what the actual requirements for physicians will be, but rather what they would be if only population changes were taken into account. However, isolating the likely future effects of changes in the population is a natural first step in such predictions. Separating population effects from other effects makes clearer and more explicit the implications of the assumptions about changes in medical knowledge, technology, and delivery practices on which the predictions are based.

\section{CALCULATING THE SEPARATE EFFECTS OF POPULATION GROWTH AND}

\section{POPULATION AGING}

The framework of the previous section can be extended to allow the separate calculation of those effects associated with the growth of the population (holding constant its composition) and those associated with changes in composition (holding size constant). This separation is of some importance. One hears much about how the aging of the population is (or will be) the source of great pressure on the health care system, but less about the effects simply of population growth. Estimation of the two types of effect may thus help to sharpen understanding of how demographic change actually affects the system.

Let $\mathrm{N}_{\mathrm{t}}=\sum_{\mathrm{j}} \sum_{\mathrm{x}} \mathrm{N}_{\mathrm{jxt}}$ be the total population in year $\mathrm{t}$ and let $\mathrm{n}_{\mathrm{j} \mathrm{t}}=\mathrm{N}_{\mathrm{jxt}} / \mathrm{N}_{\mathrm{t}}$ be the proportion of the total that is of sex $j$, age $x$. Equation (1) can then be rewritten as (3) $\mathrm{R}_{\mathrm{pt}}=\mathrm{G}_{\mathrm{t}} \mathrm{D}_{\mathrm{pt}}$ 
where $G_{t}=N_{t} / N_{0}$ is an index of the contribution of population growth to the index of change in the requirements for category $p$ physicians and $D_{p t}$ is an index of the contribution of changes in the proportionate age-sex distribution, defined by

$$
\mathrm{D}_{\mathrm{pt}}=\left(\sum_{\mathrm{j}} \sum_{\mathrm{x}} \mathrm{q}_{\mathrm{pjxo}} \mathrm{n}_{\mathrm{jxt}}\right) /\left(\sum_{j} \sum_{\mathrm{x}} \mathrm{q}_{\mathrm{pjxo}} \mathrm{n}_{\mathrm{jxo}}\right)
$$

The rate of change of the $R_{p}$ index can be decomposed also into growth and distribution components. Let $\Delta$ be the difference operator over some (positive) interval, say $t$ to $t^{\prime}$. The change in $R_{p t}$ is then given by

$$
\Delta \mathrm{R}_{\mathrm{pt}}=\left(\mathrm{G}_{\mathrm{t}}+\Delta \mathrm{G}_{\mathrm{t}}\right)\left(\mathrm{D}_{\mathrm{pt}}+\Delta \mathrm{D}_{\mathrm{pt}}\right)-\mathrm{G}_{\mathrm{t}} \mathrm{D}_{\mathrm{pt}}=\mathrm{G}_{\mathrm{t}} \Delta \mathrm{D}_{\mathrm{pt}}+\mathrm{D}_{\mathrm{pt}} \Delta \mathrm{G}_{\mathrm{t}}+\Delta \mathrm{G}_{\mathrm{t}} \Delta \mathrm{D}_{\mathrm{pt}}
$$

Dividing through equation (5) by $R_{p t}=G_{t} D_{p t}$ and cancelling terms in numerators and denominators, we have

(6) $r_{p t}=g_{t}+d_{p t}+g_{t} d_{p t}$

where $r_{p t}=\Delta R_{p t} / R_{p t}, g_{t}=\Delta G_{t} / G_{t}$, and $d_{p t}=\Delta D_{p t} / D_{p t}$. Using a result from elementary calculus, the term $g_{t} d_{p t}$ vanishes as $t^{\prime}$ approaches $t$. For a positive but small interval, the term remains, but is of "small order," and the following approximation holds closely:

(7) $\mathrm{r}_{\mathrm{pt}} \simeq \mathrm{g}_{\mathrm{t}}+\mathrm{d}_{\mathrm{pt}}$

where the error of approximation is $g_{t} d_{p t}$.

In similar fashion, equation (2) can be rewritten as

(8) $\mathrm{R}_{\mathrm{t}}=\mathrm{G}_{\mathrm{t}} \mathrm{D}_{\mathrm{t}}$

where $D_{t}$ is defined by

(9) $\mathrm{D}_{\mathrm{t}}=\sum_{\mathrm{p}} \mathrm{w}_{\mathrm{po}} \mathrm{D}_{\mathrm{pt}}$

and the rate of change of the $R$ index can be expressed as 


$$
r_{t} \simeq g_{t}+d_{t}
$$

with error of approximation $g_{t} d_{t}$.

The error of approximation in (7) or (10) results from the interaction of the two components; it cannot be assigned entirely to either. A reasonable procedure is to assign half to each component, and that is what we do below in decomposing index changes calculated over 5-year intervals. A check of our results showed that the error of approximation never exceeds $3 / 10$ of a percentage point in the calculated 5-year rates of change, and most frequently is in the range 0 to $2 / 10$ of a percentage point. The adjustment to each component is therefore in the range 0 to $3 / 20$ of a percentage point.

\section{EFFECTS OF POPULATION CHANGE ON PHYSICIAN REQUIREMENTS: AN}

\section{OVERALL ASSESSMENT}

The effects of population change on the overall requirements for physicians, all categories combined, are shown in Table 2 for the period 1980-2020. The table includes an index of requirements, holding all factors constant except the population (based on equation (2)). It includes also 5-year growth rates and their decomposition into population growth and aging components (based on equations (8) - (10); the distribution effects actually relate to changes in age and sex distribution but since almost all of the effects derive from population aging we refer to them that way). Seven sets of requirements projections are shown, derived from the seven sets of population projections summarized in Table 1.

Looking back, population change -- growth and aging combined -- would have pushed the requirements for physicians up by some 41 percent between 1980 and 2000 , abstracting 
from other influences. The pattern mirrors closely the growth of the population, and indeed population growth was the dominant demographic influence over the two decades; it accounts for just over four-fifths of the total rise in the index in that period. Even in the most recent 5-year period, 1995-2000, when so much has been heard about the effects of aging on the health care system, population growth would have accounted for more than four-fifths of the overall increase, aging for less than one-fifth. The frequent emphasis on aging as the principal cause of increased requirements for physician services would thus seem to be unwarranted.

The effects of aging will increase in the next two decades, whichever of the seven projections one chooses to look at. Nevertheless, they will continue to be smaller than the effects of population growth. Based on our standard projection, growth would account for about seven-tenths of the population-related increase in requirements between 2000 and 2020, aging for three-tenths. Even using the "low immigration" projection, which yields the highest ratio of aging to growth effects, the share of the latter would still be in excess of six-tenths. The likely future effects of aging are by no means negligible but they should be seen in proper perspective.

Putting the two effects together, growth and aging, the increase in the total requirements index between 2000 to 2020 is projected to be in the range 25 to 34 percent; our "standard" projection puts it at 30. Compared with the 41 percent increase between 1980 and 2000, that implies a significant reduction rather than ancrease over the next two decades. Looking within the periods, at no time over the next two decades do the 5year rates of increase equal those of the 1980s. The highest projected 5-year rate among all 
of the seven alternative projections is 8.0 percent in 2005-10 (the "high immigration" projection), lower than the 8.6 percent rate in $1980-85$ and the 12.3 percent rate in $1985-90$ (and only slightly greater than the 7.8 percent rate in 1990-95). What is going to happen, then -- and all seven of the projections tell the same general story -- is that the higher rates of increase resulting from aging will be more than offset by the lower rates associated with population growth, with the result that one can expect the overall rate of increase in requirements to be lower over the next two decades. If the actual requirements for physician services is to rise more rapidly over that period the reasons must lie elsewhere than in the changing size and age distribution of the population.

\section{EFFECTS ON MAJOR GROUPS OF PHYSICIANS}

The effects of population change are spread quite unevenly among different categories of physicians. We begin by considering six major groups: General Practice, Internal Medicine, Other Medical Specialties, General Surgery, Other Surgical Specialties, and Laboratory Medicine. Results for those groups are shown in Table 3, based on the "standard" population projection.

The effects of population growth are necessarily the same for all of the groups. The differences among the groups are therefore the result of differences in their response to changes in age-sex distribution, and since changes in sex distribution are inconsequential, that means their response to population aging. The groups that are most affected by aging are Internal Medical Specialties and General Surgery: the requirements index for the former increases by 46 percent between 2000 and 2020 (compared with 30 percent for all 
physicians), the index for the latter by 44 percent. Those two groups are also the ones that show the largest percentage increases in the indexes over the previous twenty years, 55 percent and 52 percent, respectively. While the population-induced increases in requirements for Internal Medical Specialties and General Surgery can safely be predicted to be very large over the next two decades, they will likely be no larger than the increases in the preceding two.

\section{EFFECTS ON INDIVIDUAL CATEGORIES OF PHYSICIANS}

Results are shown in Table 4 for all nineteen of the physician categories that we take separate account of in our analysis, again based on the "standard" population projection. Only the overall effects of population change are shown. However, since the effects of growth are the same for all, the differences in the indexes are again the result entirely of population aging.

The projected differences in the indexes are more pronounced at the level of individual categories than at the major group level, as one would expect. Leading the list are Thoracic/Cardiovascular Surgery, with a projected 20-year increase of about 60 percent; close behind are Ophthalmology and Urology, both with increases of 50 percent. (Again, though, as large as these projected increases are, they are still smaller than the corresponding increases in 1980-2000.) At the other extreme are Pediatrics (only a 4 percent increase projected), Obstetrics/Gynecology (14 percent), and Psychiatry (18 percent). 


\section{CONCLUSION}

Contrary to popular belief, the overall rate of increase in the requirements for physicians (all categories combined) resulting from population change can be expected to be significantly lower in the period 2000-2020 than in the preceding two decades. Population aging will tend to raise the overall rate but it will be more than offset by slower population growth. The main effect of aging will be on the distribution of requirements among different categories of physicians. Some will experience population-induced increases well above the average, others will experience increases well below; the projected increases range from 60 percent for Thoracic/Cardiovascular Surgery down to 4 percent for Pediatrics, based on our "standard" demographic assumptions.

We emphasize, in closing, that our projections should not be viewed as predictions of what future increases in the requirements for physicians will actually be. They are projections of the "pure" effects of population change, holding constant all other factors. Actual requirements, as they are perceived to be ten or twenty years from now, will depend on advances in medical knowledge, technology, and practice norms, as well as population change. 


\section{APPENDIX: THE ONTARIO POPULATION PROJECTIONS}

\section{Projection 1 (Standard)}

The total fertility rate (live births per woman) is constant at its 1997 level of 1.528 . Agesex-specific mortality rates decline such that male life expectancy rises from 76.6 years in 2000 to 79.5 in 2020 , female life expectancy from 81.7 years to 83.0. Consistent with stated government target levels, total immigration to Canada is set at 200 thousand per year in 2000 , rises linearly to 225 thousand by 2005 , and remains constant at that level thereafter; Ontario's share of the total is held constant at the average 1994-99 level of 53.9 percent. Emigration from Ontario to other countries is held at .26 percent of the population. Net migration to and from the rest of Canada is set at 4.7 thousand in $\mathbf{2 0 0 0}$, declines linearly to

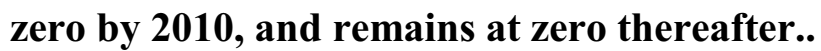

\section{Projection 2 (High Mortality)}

Male life expectancy rises to 78.6 in $\mathbf{2 0 2 0}$, female life expectancy to 82.2 . Otherwise the same as Projection 1.

Projection 3 (Low Mortality)

Male life expectancy rises to 80.3 in 2020 , female life expectancy to 83.7 . Otherwise the same as Projection 1.

\section{Projection 4 (High Fertility)}

The total fertility rate rises linearly from 1.528 in 2001 to 1.940 in 2020 . Otherwise the same as Projection 1. 


\section{Projection 5 (Low Fertility)}

The total fertility rate falls linearly from 1.528 in 2001 to 1.300 in 2020 . Otherwise the same as Projection 1.

Projection 6 (High Immigration)

Total immigration to Canada rises linearly to 275 thousand per year by 2005, remains constant thereafter; Ontario's share maintained at 53.9 percent. Otherwise the same as

Projection 1.

Projection 7 (Low Immigration)

Total immigration to Canada falls linearly to 175 thousand per year by 2005, remains constant thereafter; Ontario's share maintained at 53.9 percent. Otherwise the same as Projection 1. 


\section{REFERENCES}

Banerjee, Kali S. (1975), Cost of Living Index Numbers: Practice, Precision, and Theory, New York: Marcel Dekker, Inc.

Canadian Institute for Health Information (1998), National Health Expenditure Trends, 1975-1998.

Denton, Frank T., Christine H. Feaver, and Byron G. Spencer (1994), “EconomicDemographic Projection and Simulation: A Description of the MEDS System of Models," in K. Vaninadha Rao and Jerry W. Wicks (eds.), $\underline{\text { Studies in Applied }}$ Demography: Proceedings of the International Conference on Applied Demography, Bowling Green University.

Denton, Frank T., Christine H. Feaver, and Byron G. Spencer (1997), 'PMEDS-D Users' Manual," Research Report No. 326, Institute for Quantitative Studies in Economics and Population, McMaster University.

Denton, Frank T., Amiram Gafni, and Byron G. Spencer (1992), "Resource Requirements and Availability: An Integrated System of Models for Health Care Planning," in M.K. Chytil, G. Duru, W. van Eimeren, and Ch. D. Flagle, eds., Health Systems: The Challenge of Change (Omnipress).

Denton, Frank T., Amiram Gafni, and Byron G. Spencer (1993), “The SHARP Computer System: A Tool for Resource Planning in the Health Care Sector," in M. Malek, J. Rasquinha, and P. Vacani, eds., Strategic Issues in Health Care Management (John Wiley and Sons). 
Denton, Frank T., Amiram Gafni, and Byron G. Spencer (1994), "System for Health Area Resource Planning (SHARP): An Application to Ontario Medical School Enrolment," Canadian Medical Association Journal, Vol. 151, No. 1, pp. 39-45.

Denton, Frank T., Amiram Gafni, and Byron G. Spencer (1995a), "Physician Supply in Ontario: Further Observations on SHARP and the SHARP Projections," Canadian Medical Association Journal, Vol. 152, No. 9, pp. 1389-91.

Denton, Frank T., Amiram Gafni, and Byron G. Spencer (1995b), "The SHARP Way to Plan Health Care Services: A Description of the System and Some Illustrative Applications in Nursing Human Resource Planning," Socio-Economic Planning Sciences, Vol. 29, No. 2, pp. 125-37.

Greenberg, Leonard, and James M. Cultice (1997), “Forecasting the Need for Physicians in the United States: The Health Resources and Services Administration's Physician Requirements Model," Health Services Research, Vol. 31, pp. 723-37.

Sloan, Frank A. (1994), “Review” of Wolfe (1993), Journal of Economic Literature, Vol. XXXII, pp. 1254-55.

Wolfe, John R. (1993), The Coming Health Crisis: Who Will Pay for Care for the Aged in the Twenty-first Century?, University of Chicago Press. 
FIGURE 1: AGE PROFILES OF THE UTILIZATION OF PHYSICIAN SERVICES (FEE PAYMENTS PER CAPITA), BY CATEGORY OF PHYSICIAN: ONTARIO, 1995
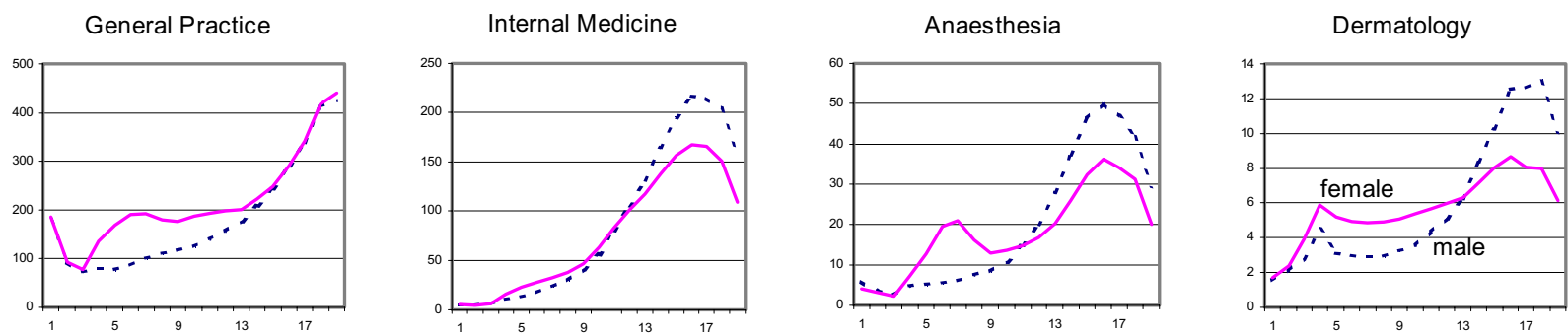

Neurology

Pediatrics
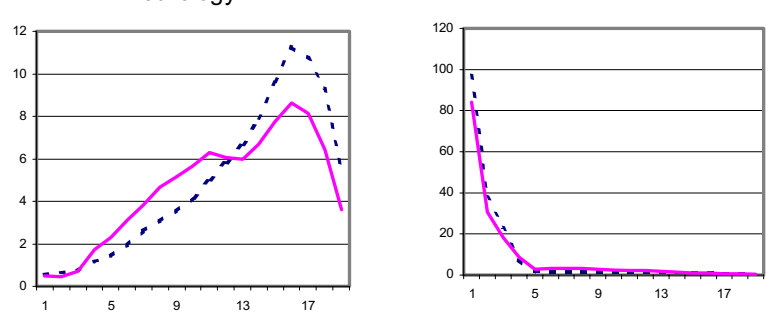

Physical Medicine

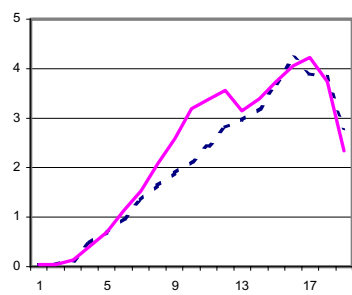

Psychiatry

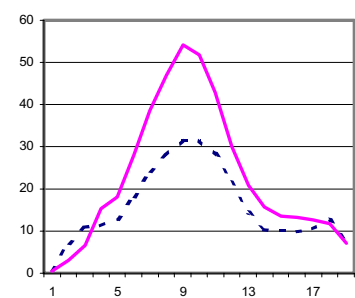

General Surgery

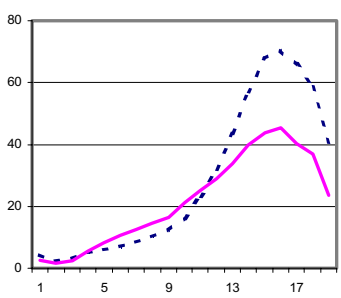

Neurosurgery
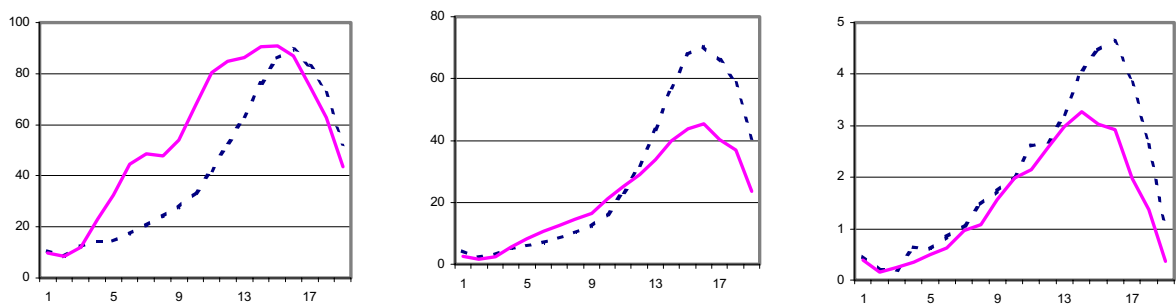

Obs/Gyn

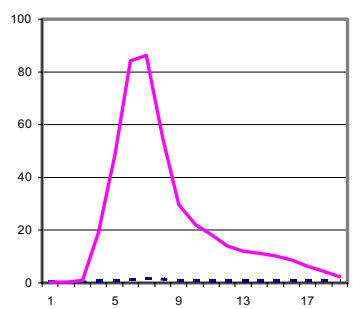

Ophthalmology

Orthopedic Surgery

Otolaryngology
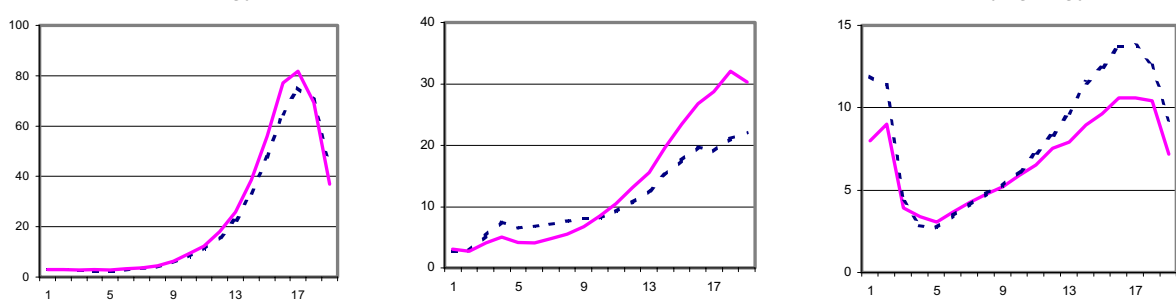

Plastic Surgery
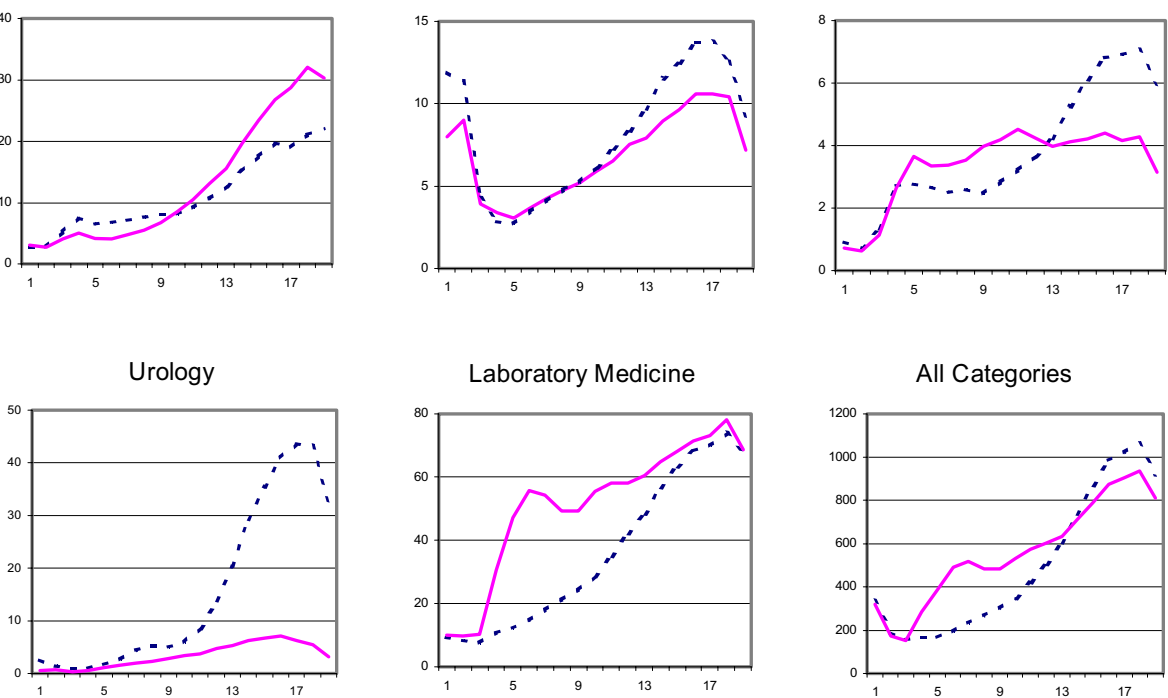

Laboratory Medicine

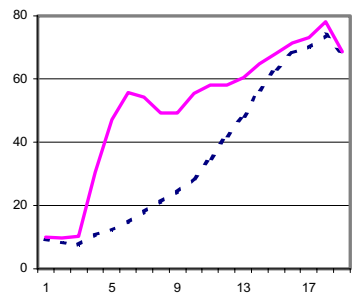

All Categories

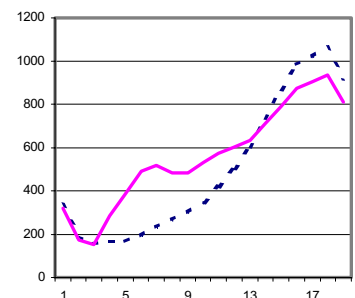

Note: Age groups are shown on the horizontal axes, coded 1 for $0-4,2$ for $5-9, \ldots, 18$ for $85-89$, and 19 for 90 and over. Fee payments per capita (in dollars) are shown on the vertical axes. 
TABLE 1: THE POPULATION OF ONTARIO AND ITS AGE CHARACTERISTICS, ACTUAL AND PROJECTED, $1980-2020$

\begin{tabular}{|c|c|c|c|c|c|c|c|}
\hline & \multicolumn{3}{|c|}{ Population } & & \multicolumn{3}{|c|}{ Age Distribution (\%) } \\
\hline & $\begin{array}{r}\text { Number } \\
\text { ('000) }\end{array}$ & $\begin{array}{r}\text { Index } \\
(2000= \\
100.0)\end{array}$ & $\begin{array}{r}5 \text {-year } \\
\text { growth } \\
\text { rate }(\%)\end{array}$ & $\begin{array}{r}\text { Median } \\
\text { age }\end{array}$ & $\begin{array}{r}\text { Under } \\
15\end{array}$ & $55-74$ & $\begin{array}{r}75 \text { and } \\
\text { older }\end{array}$ \\
\hline \multicolumn{8}{|l|}{ Actual Population } \\
\hline 1980 & 8745 & 75.1 & --- & 30.0 & 22.1 & 15.1 & 3.7 \\
\hline 1985 & 9297 & 79.8 & 6.3 & 31.6 & 20.5 & 16.0 & 4.1 \\
\hline 1990 & 10300 & 88.5 & 10.8 & 32.9 & 20.1 & 15.7 & 4.5 \\
\hline 1995 & 10965 & 94.2 & 6.5 & 34.6 & 20.3 & 15.9 & 4.8 \\
\hline 2000 & 11644 & 100.0 & 6.2 & 36.6 & 19.5 & 16.2 & 5.6 \\
\hline \multicolumn{8}{|c|}{ Projection 1 (Standard) } \\
\hline 2005 & 12276 & 105.4 & 5.4 & 38.3 & 18.1 & 17.8 & 6.2 \\
\hline 2010 & 12896 & 110.8 & 5.1 & 39.5 & 16.6 & 19.7 & 6.5 \\
\hline 2015 & 13485 & 115.8 & 4.6 & 40.5 & 15.9 & 22.1 & 6.7 \\
\hline 2020 & 14048 & 120.6 & 4.2 & 41.4 & 15.7 & 24.3 & 7.2 \\
\hline \multicolumn{8}{|c|}{ Projection 2 (High Mortality) } \\
\hline 2005 & 12273 & 105.4 & 5.4 & 38.3 & 18.1 & 17.8 & 6.1 \\
\hline 2010 & 12886 & 110.7 & 5.0 & 39.5 & 16.6 & 19.7 & 6.4 \\
\hline 2015 & 13462 & 115.6 & 4.5 & 40.4 & 15.9 & 22.0 & 6.6 \\
\hline 2020 & 14002 & 120.3 & 4.0 & 41.3 & 15.8 & 24.3 & 7.1 \\
\hline \multicolumn{8}{|c|}{ Projection 3 (Low Mortality) } \\
\hline 2005 & 12279 & 105.5 & 5.5 & 38.3 & 18.1 & 17.8 & 6.2 \\
\hline 2010 & 12905 & 110.8 & 5.1 & 39.5 & 16.6 & 19.7 & 6.5 \\
\hline 2015 & 13508 & 116.0 & 4.7 & 40.6 & 15.9 & 22.1 & 6.8 \\
\hline 2020 & 14092 & 121.0 & 4.3 & 41.5 & 15.7 & 24.4 & 7.4 \\
\hline \multicolumn{8}{|c|}{ Projection 4 (High Fertility) } \\
\hline 2005 & 12291 & 105.6 & 5.6 & 38.2 & 18.2 & 17.7 & 6.1 \\
\hline 2010 & 12971 & 111.4 & 5.5 & 39.3 & 17.1 & 19.6 & 6.4 \\
\hline 2015 & 13670 & 117.4 & 5.4 & 40.0 & 17.1 & 21.8 & 6.6 \\
\hline 2020 & 14396 & 123.6 & 5.3 & 40.5 & 17.7 & 23.7 & 7.1 \\
\hline \multicolumn{8}{|c|}{ Projection 5 (Low Fertility) } \\
\hline 2005 & 12268 & 105.4 & 5.4 & 38.3 & 18.1 & 17.8 & 6.2 \\
\hline 2010 & 12855 & 110.4 & 4.8 & 39.6 & 16.3 & 19.8 & 6.5 \\
\hline 2015 & 13383 & 114.9 & 4.1 & 40.8 & 15.3 & 22.2 & 6.7 \\
\hline 2020 & 13857 & 119.0 & 3.5 & 41.9 & 14.6 & 24.6 & 7.3 \\
\hline \multicolumn{8}{|c|}{ Projection 6 (High Immigration) } \\
\hline 2005 & 12359 & 106.1 & 6.1 & 38.1 & 18.1 & 17.7 & 6.1 \\
\hline 2010 & 13124 & 112.7 & 6.2 & 39.2 & 16.7 & 19.5 & 6.4 \\
\hline 2015 & 13868 & 119.1 & 5.7 & 40.1 & 16.1 & 21.7 & 6.5 \\
\hline 2020 & 14590 & 125.3 & 5.2 & 40.9 & 16.0 & 23.7 & 7.0 \\
\hline \multicolumn{8}{|c|}{ Projection 7 (Low Immigration) } \\
\hline 2005 & 12193 & 104.7 & 4.7 & 38.4 & 18.1 & 17.8 & 6.2 \\
\hline 2010 & 12667 & 108.8 & 3.9 & 39.8 & 16.5 & 19.9 & 6.6 \\
\hline 2015 & 13102 & 112.5 & 3.4 & 41.0 & 15.7 & 22.5 & 6.9 \\
\hline 2020 & 13507 & 116.0 & 3.1 & 42.0 & 15.4 & 24.9 & 7.5 \\
\hline
\end{tabular}


TABLE 2: THE EFFECTS OF POPULATION CHANGE ON THE REQUIREMENTS FOR PHYSICIANS: ALL CATEGORIES OF PHYSICIANS

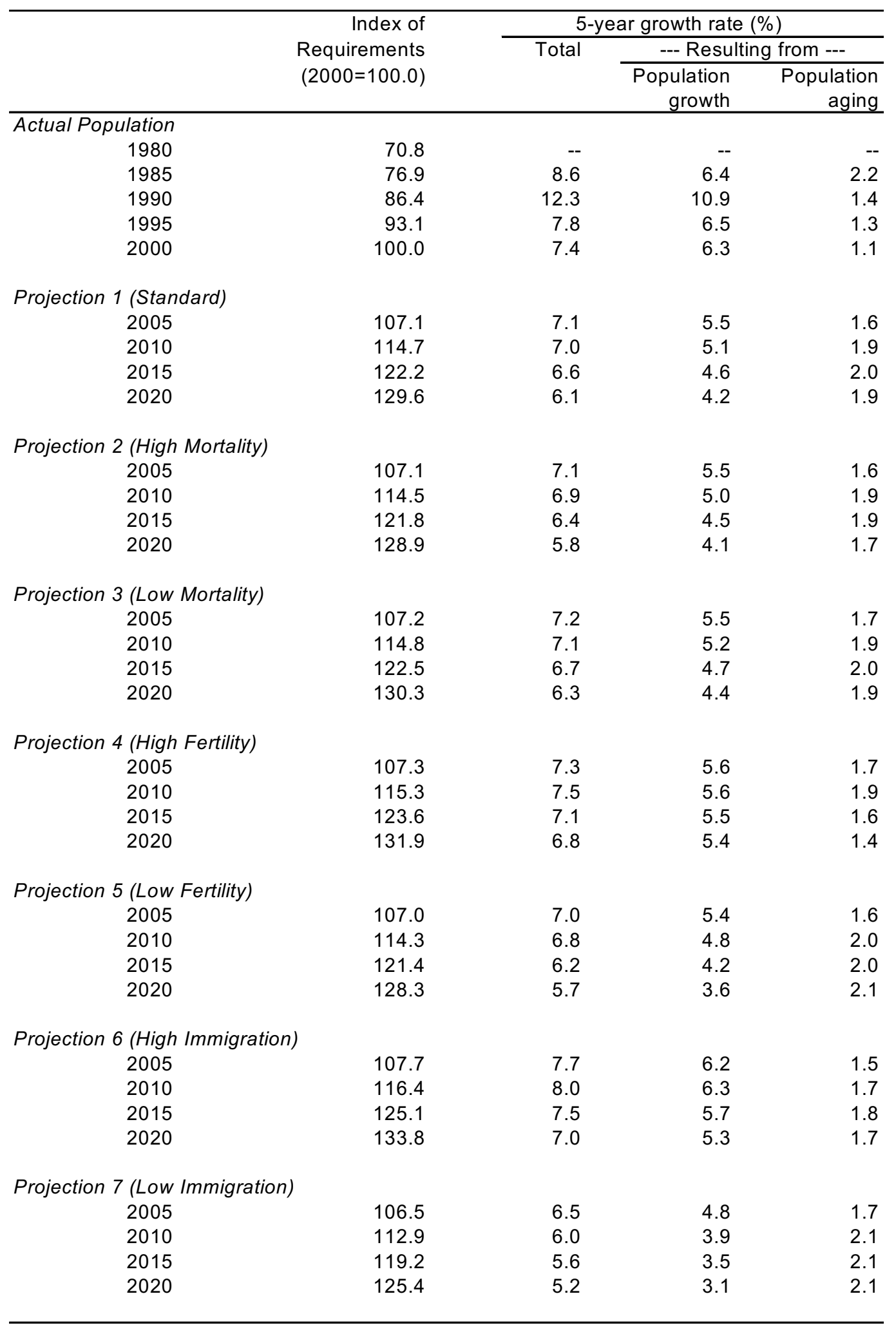


TABLE 3: THE EFFECTS OF POPULATION CHANGE ON THE REQUIREMENTS FOR PHYSICIANS: MAJOR PHYSICIAN GROUPS

\begin{tabular}{|c|c|c|c|c|c|c|c|c|c|}
\hline & \multicolumn{5}{|c|}{ Based on actual population } & \multicolumn{4}{|c|}{ Projected } \\
\hline & 1980 & 1985 & 1990 & 1995 & 2000 & 2005 & 2010 & 2015 & 2020 \\
\hline \multicolumn{10}{|l|}{ General Practice } \\
\hline Index of requirements & 71.4 & 77.3 & 86.8 & 93.3 & 100.0 & 106.9 & 114.2 & 121.4 & 128.5 \\
\hline 5-year growth rate (\%) & -- & 8.4 & 12.2 & 7.6 & 7.2 & 6.9 & 6.8 & 6.3 & 5.9 \\
\hline -- resulting from population growth & -- & 6.4 & 10.9 & 6.5 & 6.3 & 5.5 & 5.1 & 4.6 & 4.2 \\
\hline -- resulting from population aging & -- & 2.0 & 1.3 & 1.1 & 0.9 & 1.4 & 1.7 & 1.7 & 1.7 \\
\hline \multicolumn{10}{|l|}{ Internal Medicine } \\
\hline Index of requirements & 64.5 & 71.8 & 81.4 & 90.0 & 100.0 & 110.7 & 122.1 & 134.0 & 146.2 \\
\hline 5-year growth rate (\%) & -- & 11.3 & 13.4 & 10.6 & 11.1 & 10.7 & 10.3 & 9.8 & 9.1 \\
\hline -- resulting from population growth & -- & 6.4 & 10.9 & 6.5 & 6.3 & 5.5 & 5.1 & 4.6 & 4.2 \\
\hline -- resulting from population aging & -- & 4.9 & 2.5 & 4.1 & 4.8 & 5.2 & 5.2 & 5.2 & 4.9 \\
\hline \multicolumn{10}{|l|}{ Other Medical Specialties } \\
\hline Index of requirements & 70.1 & 76.1 & 85.9 & 93.1 & 100.0 & 106.7 & 113.2 & 119.4 & 125.5 \\
\hline 5-year growth rate (\%) & -- & 8.6 & 12.9 & 8.3 & 7.5 & 6.7 & 6.1 & 5.5 & 5.1 \\
\hline -- resulting from population growth & -- & 6.4 & 10.9 & 6.5 & 6.3 & 5.5 & 5.1 & 4.6 & 4.2 \\
\hline -- resulting from population aging & -- & 2.2 & 2.0 & 1.8 & 1.2 & 1.2 & 1.0 & 0.7 & 0.9 \\
\hline \multicolumn{10}{|l|}{ General Surgery } \\
\hline Index of requirements & 65.6 & 72.8 & 82.5 & 90.7 & 100.0 & 109.9 & 120.7 & 132.1 & 143.8 \\
\hline 5-year growth rate (\%) & -- & 11.0 & 13.3 & 10.0 & 10.2 & 9.9 & 9.8 & 9.5 & 8.9 \\
\hline -- resulting from population growth & -- & 6.4 & 10.9 & 6.5 & 6.3 & 5.5 & 5.1 & 4.6 & 4.2 \\
\hline -- resulting from population aging & -- & 4.6 & 2.4 & 3.5 & 3.9 & 4.4 & 4.7 & 4.9 & 4.7 \\
\hline \multicolumn{10}{|l|}{ Other Surgical Specialties } \\
\hline Index of requirements & 71.2 & 78.5 & 88.6 & 94.2 & 100.0 & 106.3 & 113.7 & 121.6 & 129.8 \\
\hline 5-year growth rate (\%) & -- & 10.3 & 12.9 & 6.3 & 6.2 & 6.3 & 6.9 & 7.0 & 6.7 \\
\hline -- resulting from population growth & -- & 6.4 & 10.9 & 6.5 & 6.3 & 5.5 & 5.1 & 4.6 & 4.2 \\
\hline -- resulting from population aging & -- & 3.9 & 2.0 & -0.2 & 0.0 & 0.8 & 1.8 & 2.4 & 2.5 \\
\hline \multicolumn{10}{|l|}{ Laboratory Medicine } \\
\hline Index of requirements & 69.6 & 76.2 & 85.6 & 92.4 & 100.0 & 108.0 & 116.4 & 124.5 & 132.2 \\
\hline 5-year growth rate (\%) & -- & 9.5 & 12.4 & 7.9 & 8.3 & 8.0 & 7.8 & 7.0 & 6.2 \\
\hline -- resulting from population growth & -- & 6.4 & 10.9 & 6.5 & 6.3 & 5.5 & 5.1 & 4.6 & 4.2 \\
\hline -- resulting from population aging & -- & 3.1 & 1.5 & 1.4 & 2.0 & 2.5 & 2.7 & 2.4 & 2.0 \\
\hline
\end{tabular}

Note: Projections of requirements are based on population Projection 1 (Standard). Indexes have value 100.0 in 2000. 
TABLE 4: THE EFFECTS OF POPULATION CHANGE ON THE REQUIREMENTS FOR PHYSICIANS: INDIVIDUAL PHYSICIAN CATEGORIES

\begin{tabular}{|c|c|c|c|c|c|c|c|c|c|}
\hline & \multicolumn{5}{|c|}{ Based on actual population } & \multicolumn{4}{|c|}{ Projected } \\
\hline & 1980 & 1985 & 1990 & 1995 & 2000 & 2005 & 2010 & 2015 & 2020 \\
\hline General Practice & 71.4 & 77.3 & 86.8 & 93.3 & 100.0 & 106.9 & 114.2 & 121.4 & 128.5 \\
\hline \multicolumn{10}{|l|}{ Medical Specialties } \\
\hline Internal Medicine & 64.5 & 71.8 & 81.4 & 90.0 & 100.0 & 110.7 & 122.1 & 134.0 & 146.2 \\
\hline Anaesthesia & 68.2 & 75.4 & 85.2 & 92.3 & 100.0 & 108.1 & 117.4 & 127.4 & 138.1 \\
\hline Dermatology & 72.1 & 77.4 & 86.0 & 92.5 & 100.0 & 107.6 & 115.2 & 122.6 & 130.2 \\
\hline Neurology & 66.3 & 73.2 & 83.1 & 91.1 & 100.0 & 108.8 & 117.6 & 126.4 & 135.4 \\
\hline Pediatrics & 85.8 & 87.8 & 97.3 & 101.9 & 100.0 & 98.6 & 98.8 & 100.9 & 103.9 \\
\hline Physical Medicine & 64.9 & 72.1 & 82.0 & 90.5 & 100.0 & 109.5 & 118.7 & 127.5 & 136.1 \\
\hline Psychiatry & 68.5 & 74.7 & 85.0 & 92.4 & 100.0 & 106.3 & 111.2 & 114.8 & 117.9 \\
\hline Radiology & 68.2 & 74.8 & 84.2 & 91.6 & 100.0 & 108.7 & 117.9 & 126.9 & 135.5 \\
\hline \multicolumn{10}{|l|}{ Surgical Specialties } \\
\hline General Surgery & 65.6 & 72.8 & 82.5 & 90.7 & 100.0 & 109.9 & 120.7 & 132.1 & 143.8 \\
\hline Neurosurgery & 66.2 & 73.1 & 82.8 & 91.0 & 100.0 & 109.3 & 119.1 & 129.1 & 138.7 \\
\hline Obstetrics/Gynecology & 77.6 & 85.5 & 96.1 & 98.4 & 100.0 & 102.4 & 106.5 & 110.8 & 114.1 \\
\hline Ophthalmology & 62.6 & 70.2 & 80.2 & 89.5 & 100.0 & 110.8 & 122.2 & 134.9 & 150.0 \\
\hline Orthopedic Surgery & 68.8 & 75.0 & 84.2 & 91.5 & 100.0 & 108.7 & 117.7 & 126.8 & 136.2 \\
\hline Otolaryngology & 71.3 & 76.4 & 85.8 & 93.2 & 100.0 & 105.9 & 112.6 & 119.9 & 127.6 \\
\hline Plastic Surgery & 71.4 & 77.4 & 86.3 & 92.6 & 100.0 & 107.7 & 115.5 & 122.8 & 129.6 \\
\hline Thoracic/Cardiovascular Surgery & 62.9 & 70.7 & 80.2 & 89.4 & 100.0 & 111.8 & 126.0 & 142.6 & 159.8 \\
\hline Urology & 63.7 & 71.3 & 81.5 & 90.4 & 100.0 & 110.4 & 122.2 & 135.4 & 149.8 \\
\hline Laboratory Medicine & 69.6 & 76.2 & 85.6 & 92.4 & 100.0 & 108.0 & 116.4 & 124.5 & 132.2 \\
\hline
\end{tabular}


No. 338: A Bayesian Approach for Measuring Economies of

M.W.L. Chan

Scale with Application to Large Canadian Banks

D. Li

D.C. Mountain

No. 339: Economic Costs of Population Aging

F.T. Denton

B.G. Spencer

No. 340: Population Aging and Its Economic Costs: A Survey of

F.T. Denton the Issues and Evidence

B.G. Spencer

No. 341: How Much Help is Exchanged in Families? Towards

C.J. Rosenthal an Understanding of Discrepant Research Findings

L.O. Stone

No. 342: Did Tax Flattening Affect RRSP Contributions?

M.R. Veall

No. 343: Families as Care-Providers Versus Care-Managers?

Gender and Type of Care in a Sample of Employed Canadians

C.J. Rosenthal

A. Martin-

Matthews

No. 344: Alternatives for Raising Living Standards

W. Scarth

No. 345: Mixed Estimation When the Model And/Or Stochastic Restrictions are Nonlinear

F.T. Denton

No. 346: A Model of Energy Demand in the U.S. Commercial Sector with Declining Rate Schedules

F.T. Denton

D.C. Mountain

B.G. Spencer

No. 347: Projections of the Population and Labour Force to 2046: Canada

F.T. Denton

C.H. Feaver

B.G. Spencer

No. 348: Projections of the Population and Labour Force to 2046: The Provinces and Territories

F.T. Denton

C.H. Feaver

B.G. Spencer

No. 349: Location of Adult Children as an Attraction for Black and White Elderly Migrants in the United States

K.-L. Liaw

W.H. Frey

J.-P. Lin

No. 350: The Effects of Drug Subsidies on Out-of-Pocket

T.F. Crossley

Prescription Drug Expenditures by Seniors: Regional Evidence from Canada

P. Grootendorst

S. Korkmaz

M.R. Veall 
No. 351: Describing Disability among High and Low Income

P. Raina Status

Older Adults in Canada

M. Wong

L.W. Chambers

M. Denton

A. Gafni

No. 352: Some Demographic Consequences of Revising the

F.T. Denton

Definition of 'Old' to Reflect Future Changes in Life

B.G. Spencer

Table Probabilities

No. 353: The Correlation Between Husband's and Wife's

Education: Canada, 1971-1996

L. Magee

J. Burbidge

L. Robb

No. 354: The Effect of Marginal Tax Rates on Taxable Income:

M.-A. Sillamaa

A Panel Study of the 1988 Tax Flattening in Canada

M.R. Veall

No. 355: Population Change and the Requirements for

F.T. Denton

Physicians: The Case of Ontario
A. Gafni
B.G. Spencer 